Pensares em Revista, ISSN 2317-2215

\title{
POESIA E ENSINO: "O QUE SERÁ PARA UMA BORBOLETA REBOCAR UM BATELÃO!"
}

\author{
Armando Ferreira GENS FILHO \\ (Universidade do Estado do Rio de Janeiro) \\ armandogens@gmail.com
}

\begin{abstract}
Resumo: Chega-se à primeira década do século XXI com muitas dúvidas sobre o ensino de poesia. Um bombardeamento teórico e prático, em lugar de esclarecer, trouxe mais dúvidas e proporcionou uma abertura tal que já não é mais possível saber o que é literatura e tampouco definir perfis para o professor de literatura. Por sua vez, o texto literário mais do que nunca se mostra a serviço de muitas outras variantes, exibindo porosidade e mobilidade, enquanto a Literatura, que nunca aceitou ser uma disciplina, tornou-se Estudos Literários. Diante de tantas transformações, seria produtivo repensar o ensino de poesia, porém com certa dose de desconfiança. Isto posto, este artigo tem como objetivo revisar, a partir da tradição, os caminhos do ensino de poesia na primeira década do século XXI. Para o desenvolvimento da proposta, coloca-se, inicialmente, em debate os conceitos de poesia, leitura, audição, subjetividade, de forma a repassar os pontos que contribuíram para a rarefação da poesia nos currículos e as dificuldades que afastam os alunos de um convívio maior com o gênero. Em segundo lugar, toma-se o caminho da radicalidade para sugerir mais espaço para a poesia que dialoga com outras áreas do conhecimento humano - como a computação gráfica e as ciências --, nos currículos.
\end{abstract}

Palavras-chave: Ensino. Poesia. Tecnologia.

\section{POETRY AND TEACHING: "HOW HEAVY IT IS FOR THE BUTTERFLY TO TOW A BARGE!"}

\begin{abstract}
The first decade of the 21st century brought many questions about teaching poetry. A theoretical and practical bombardment, rather than clarify, brought more questions and provided such an opening that it is no longer possible to know what literature is and neither set profiles for the professor of literature. In turn, the literary text more than ever shows the service of many other things, showing porosity and mobility, while Literature, which never accepted being a discipline, became Literary Studies. Faced with so many changes, it would be productive to rethink the teaching of poetry, but with a certain dose of mistrust. That being said, this article is aimed at reviewing, from the tradition, the paths of the teaching of poetry in the first decade of the 21st century. For the development of the proposal, initially put at issue the concepts of poetry, reading, hearing, subjectivity, in order to review the points that contributed to the rarefaction of poetry in the curricula and the difficulties that students demonstrate that they have with gender. Secondly, take the path of radicalism to suggest more space for poetry that dialogues with other areas of human knowledge - such as computer graphics and science - in the curricula.
\end{abstract}

Keywords: Teaching. Poetry. Technology.

Pensares em Revista, São Gonçalo-RJ, n. 5, pág. 5 - 25, jul./dez. 2014

DOI: http://dx.doi.org/10.12957/pr.2014.14109 


\section{1 - Fala, escuta e leitura}

Não há como fugir às interrogações, quando o tema gira em torno do ensino de poesia. Portanto, caberia indagar se, entre áreas tão distintas como ensino e poesia, é possível haver algum tipo de conjunção. Seria igualmente importante levantar suspeitas sobre a crença de que existem metodologias específicas para o ensino de poesia, assim como poderia fazer ainda certo sentido, para o desenvolvimento do tema, inquirir sobre o que se deve ensinar ao se ter como objeto de ensino a poesia. Tendo em mente tais questões, é possível vislumbrar uma aceitável correspondência entre o verso de Tomas Tranströmer -- "o que será para uma borboleta rebocar um batelão!" (TRANSTÖRMER, 2012, p. 97) — e as desconcertantes incertezas que fragilizam o ensino da poesia.

O verso do poeta sueco é de grande impacto, pois se trata de uma elaboração poética na qual os contrastes se acirram para metaforizar um dispêndio de energia e força absurdo empregado na realização de uma tarefa. De natureza antitética, os vocábulos "borboleta" e "batelão" propõem uma série de tensões entre ar e mar, entre voo e navegação, entre animal e objeto, entre força e fragilidade, entre velocidade e lentidão, assim como entre formatos e grandezas diferenciados. Vê-se, então, através de tal embate semântico, emergir uma força expressiva que comunica a intensidade do esforço que a voz lírica emprega para escapar do furacão. O verso em sua força expressional materializa a ação de um homem em busca de um abrigo para escapar da violência dos ventos e, ao mesmo tempo, revela o sentimento de fragilidade que experimenta. Por isso, ao chegar ao abrigo, pode dizer: "Mas eu já não esvoaço" (TRANSTÖRMER, 2012, p. 97).

Território minado, porque ardilosamente construído, a totalidade do texto poético desautoriza, em parte, a leitura que aqui se faz do verso isolado, já que, no contexto do poema, "borboleta" e "batelão" encarnam a luta do homem com o furacão; logo, exigindo que os sentidos metafóricos sejam retificados. No entanto, a construção metafórica da tarefa hercúlea empreendida pela voz poética não necessita ser reconfigurada. A desmedida destaca um traço da natureza humana, quando está em questão sobreviver, de modo que à medida que a potência empregada para escapar da força da natureza se esvai, a voz poética, já devidamente abrigada, valorize a invulnerabilidade da transparência: "Que 
estranha e fantástica invenção não é o vidro - está tão perto e não ser afetado..." (TRANSTÖRMER, 2012, p. 97). Mais uma vez, o contraste volta a ressurgir na cena do poema intitulado "Furacão islandês". Agora, as tensões reaparecerem na reflexão da voz poética. Porém, dentro e fora, próximo e distante logo se enfraquecem enquanto antíteses e convertem-se em oximoros (convivência dos contrários) devido à mudança de ponto de vista da voz; mudança patrocinada pela sensação de abrigo e pela "enorme janela envidraçada" que a transformam em espectadora da paisagem e de si mesma (enquadramento duplo, uma moldura isolante eu/não-eu): "Lá fora, em debandada pelo campo de lava, uma horda de corredores, vestes insufladas, gigantes e transparentes. [...] Sentado atrás do vidro, quieto, sou o meu próprio retrato." (TRANSTÖRMER, 2012, p. 97).

Toda essa digressão em torno de um verso do pictural poema de Tomas Tranströmer está, sem nenhum pudor, a serviço de pensar a poesia como objeto de ensino. Em relação à nomenclatura, fica muito claro que a poesia não se permite capturar pelo caráter didático-pedagógico que caracteriza os caminhos do ensino, uma vez que ela diz respeito a uma potência criativa que implica ultrapassagem de limites da ordem material e, sobretudo, a capacidade de imaginar, transformar e libertar um além, quase sempre não captável em toda a sua integridade pelo conhecimento, pois, como destaca Octavio Paz (1914-1998), a poesia é "uma substância impalpável, rebelde a definições" (PAZ, 1993, p.77). Jorge Luis Borges (1899-1986), em Esse ofício do verso (2000), obra que reúne as palestras proferidas pelo autor na Universidade de Harvard nos anos 60 do século passado, demonstra partilhar de posição semelhante. Ao evocar o famoso soneto de John Keats (1795-1821) intitulado “On first looking into Chapman's Homer", como um poema que trata da experiência poética, revela ao auditório que:

No exato momento em que repassava esses vigorosos versos de Keats, pensava que talvez só estivesse sendo fiel a minha memória. Talvez o verdadeiro frêmito que senti com os versos de Keats remonte àquele distante momento de minha infância em Buenos Aires, quando ouvi pela primeira vez meu pai lê-los em voz alta. E quando o fato de que a poesia, a linguagem, não era somente um meio de comunicação, mas também podia ser uma paixão e um prazer - quando isso me foi revelado, não acho que tenha compreendido as palavras, mas senti algo acontecia comigo. Acontecia não com meu simples intelecto, mas com todo o meu ser, minha carne e meu sangue. (BORGES, 2000, p.14) 
Segundo se observa, Borges rememora uma experiência pessoal única e (in) transferível vivida na leitura do soneto de Keats realizada por seu pai. A construção discursiva do escritor argentino acerca desta experiência remonta a uma combinação de vozes (a do poema e a do pai), a um ato inaugural ("primeira vez"), a imediatez da experiência que perdura no ser ("distante momento") e a um sentir, embora indefinido ("algo"), que imprime uma marca profunda na subjetividade do menino e que se mantém viva na do homem que veio a ser. Contudo, Borges tenta passar para o público que o ouve a ideia de que não há como definir o que o tocou verdadeiramente, explicando que entende a poesia como "uma experiência nova a cada vez", mas que, sendo também experimentada como "frêmito", causa um estremecimento, porque ao captar a "outra voz" (PAZ, 1993, p. 141), teve um encontro verdadeiramente poético, uma espécie de epifania, um estado que pouco dura, mas que perdura na memória.

A experiência estética vivida por Borges também coloca em destaque a importância da leitura em voz alta e o papel desempenhado pelos responsáveis na formação do leitor, assim como leva a repensar a tão apregoada indicação de textos literários por faixa etária. $O$ depoimento do poeta ressalta o vínculo da poesia com a fala, demonstrando que "a voz interior" Ihe chegara através da voz paterna, assim como revela que a experiência estética é "algo" que extrapola o que se denominaria compreensão do poema, porque, ao atingir uma camada mais profunda do ser, promove um encontro inaugural, único e intransferível com o estado poético que diz respeito a "um modo de ser da subjetividade" (DUFRENNE, 1969, p.10) e que promove uma plenitude impossível de ser definida em palavras. Tal experiência reconduz o ouvinte àquele instante primeiro em que o poeta sonoriza/oraliza as palavras em seu corpo, quando passam por sua garganta e reverberam em seu ouvido ainda livre da mudez imposta pela escrita. Esta sonorização encontra eco no seguinte fragmento destacado de Sobre arte Sobre poesia: (uma luz no chão), de Ferreira Gullar: "O poeta fala dos outros homens e pelos outros homens, mas só na medida em que fala de si mesmo, só na medida em que se confunde com os demais." (GULLAR, 2006, p.158).

Vê-se que o uso reiterado do verbo falar corrobora a ideia da existência de uma voz poética assim como assinala, no caso da poesia, a prevalência da fala sobre a escrita. No entanto, este ato só se atualiza quando o poeta estabelece 
uma ponte entre o eu e o outro, através da conjunção de forças apolíneas e dionisíacas. É necessário, então, que se reconheça a importância da leitura em voz alta e da escuta atenta das relações e das disjunções entre sons e sentidos para tentar promover encontros com o poético, isto é, abrir uma via possível de acesso àquele "estado de palavra" (BARROS, 1998, p. 35), para (re)viver um instante de imersão no âmbito de uma linguagem autônoma que extrapola padrões linguísticos empregados em uma comunicação diária, conforme observou George Steiner (1929) em "Linguística e poética":

A literatura é linguagem, mas a linguagem em uma condição de uso especial: sendo essa condição de total significação e de uma significação que é - para todo poema ou prosa literária verdadeiros - singular. Nenhuma substituição de qualquer elemento semântico, por menor que seja (considere-se o papel da tipografia em Mallarmée, em e.e.cummings), funcionará. Esses dois critérios parecem permitir uma avaliação aproximada e prática da distância entre literatura e o mundo da linguagem ou contexto léxico e sintático a partir do qual é extraída. (STEINER, 1990, p.127)

As palavras de George Steiner redobram a ênfase que se deu à leitura em voz alta como uma via de acesso à poesia, pois é no âmbito da escuta atenta que o ouvinte também pode captar a singularidade da linguagem poética de forma global e plena, sem que o material linguístico sofra adulterações como as promovidas pela prática corrente da paráfrase e que, durante a escuta, fora da moldura imposta ao poema impresso, este mesmo ouvinte sinta as palavras reverberando em seu corpo, com a mesma intensidade que a voz poética de "Furacão islandês" experimenta a força e a leveza que o vento lhe impõe. Esta imagem vigorosa não é apenas mais uma metáfora a hipertrofiar a força da experiência com o poético, mas, sobretudo, uma metáfora a sublinhar que a leitura em voz alta pode conduzir o ouvinte ao olho do furacão poema e ali experimentar a tal singularidade da linguagem poética mencionada por Steiner, ouvindo no mesmo o diferente ou até o estranho; aquele ruído, o quase impronunciável, a sobreposição de vozes como ocorre na experimentação sonora patrocinada por Ricardo Domeneck, no poema intitulado "Dos sentidos do som": "Esamrof aedíuqro amu/ Anaidilcuieitna/ Ahnizos edrev me" (DOMENECK, 2009, p.8). Assim procedendo, a leitura em voz alta torna-se um instrumento de 
afinação de ouvidos para livrar o poema da mudez a ele imposta pelo ato de impressão.

\section{2 - Estatísticas e imponderáveis}

No final do século XX, Octavio Paz, em A outra voz (1993), indagou: "quantos e quem são os que leem livros de poemas?" (p.77). Para ele, estas seriam perguntas que não poderiam estar ausentes de qualquer incursão pelos domínios da poesia, especialmente no que diz respeito à receptividade do gênero desde a época em que fazia parte da vida humana porque atrelado à mitologia, à religião, à formação dos povos, entre outros tantos pontos ressaltados pelo crítico mexicano.

Recorrendo a dedicatórias, a descrições de etnólogos, a fatos históricos, ao prefácio da antologia de poemas - New poets of England and America (1957) — editada por Donald Hall (1928) e ao ensaio de Pere Gimferrer (1945) intitulado "La poesía y el libro", Octavio Paz traz à tona uma série de informações relacionadas ao mercado editorial, às edições modestas, às expectativas de poetas em relação aos leitores, como também coloca em evidência a hostilidade e a indiferença com que um tipo de público vê a poesia.

Porém, a dinâmica de investir em diferentes perspectivas só vem demonstrar que os resultados computados em cifras e estatísticas mais acirram as contradições do que as neutralizam, revelando um contexto marcadamente paradoxal, sobretudo quando se envereda pelos intrincados caminhos da recepção para saber quem são e quantos são os leitores de poesia. Mesmo que o crítico recorra à história, pela segurança que a ordenação da memória segundo uma lógica com encaixes perfeitos oferece, as contradições permanecem. Desde que a poesia foi sendo apartada da vida e das práticas sociais e à medida que os povos foram deixando de cantá-la e de dançá-la, a tradição poética também deixou de ser concebida como parte da formação escolar dos jovens, já que antes,

ao lado da educação cívica e religiosa e dos exercícios bélicos, a poesia era uma iniciação à vida adulta em suas duas vertentes:a ação e a contemplação. Cidadão, patrício, équite, mandarim, tecutli e outros nomes que designavam os grupos e categorias sociais que dirigiam os assuntos públicos das antigas sociedades, na paz e na guerra: todos eles eram

Pensares em Revista, São Gonçalo-RJ, n. 5, pág. 5 - 25, jul./dez. 2014 
educados e modelados em uma tradição poética que inspirava seus discursos como seus atos. (PAZ, 1993, p.97-8)

Evidentemente, há outros pontos que contribuem para o afastamento da poesia, a saber: a determinação dos estilos de época que encastelaram a poesia; a derrocada da formação humanística; o movimento do mercado editorial que investe em fórmulas de padronização de público e de obras; os momentos de grande elitização das artes - fatores que devem ser considerados porque acarretam um acanhamento do público leitor e empanam a presença da poesia. Contudo, por mais que se tente buscar estabelecer quantos e quem são os leitores de poesia, a pesquisa estará sempre ameaçada por uma resposta que venha alterar-Ihe cifras e estatísticas e, consequentemente, desautorizá-la.

A investigação revela que existe, em cada época da história humana, uma oscilação tanto do número de leitores quanto de seus respectivos perfis. A pergunta proposta por Octavio Paz é muito instigante do ponto de vista das proposições teóricas que se enlaçam em diferentes temporalidades e que podem oferecer bases para uma discussão sobre o lugar da poesia no ensino superior. Da perspectiva do que vem a ser o ensino de poesia (Isto é possível?!), interessa saber se alunos gostam de poesia. No entanto, antes de iniciar a indagação sobre o gosto, torna-se fundamental a apresentação do poema de Wislawa Szymborska (1923-2012), intitulado "Alguns gostam de poesia":

Alguns -

quer dizer que nem todos.

Nem sequer a maior parte mas sim uma minoria.

Não contando as escolas onde se tem que,

e quanto a poetas,

dessas pessoas, em mil haverá duas.

Gostam --

mas gosta-se também de sopa de esparguete, dos galanteios e da cor azul, do velho cachecol, brindar à nossa gente, fazer festas ao cão.

De poesia -

mas que é isso a poesia?

Muitas e vacilantes respostas 
já foram dadas à questão.

Por mim não sei e insisto que não sei

e esta insistência é corrimão que me salva.(SZYMBORSKA, 1998, p.279)

O poema de Wislawa Szymborska acontece através do seccionamento do titulo, recurso que menos isola do que destaca e amplia os elementos constitutivos do sintagma verbal. A voz lírica dá inicio a uma perquirição de cunho quantitativo para saber quantos gostam de poesia. Das negativas e das cifras assoma o caráter minoritário daqueles que gostam do gênero. Em seguida, levanta a questão que gostar de poesia é bem diferente de gostar das coisas que podem dar prazer e que estão ligadas às experiências afetivas costumeiras, como bem atesta o corte promovido pelo nexo adversativo: "mas gosta-se de sopas de espaguete". Mantendo o recurso de ampliação, a voz poética ao perguntar "Mas que é isso a poesia?". Uma pergunta que instiga porque o "isso" traduz uma impossibilidade de captura semântica e revela uma dificuldade de enquadramento. Portanto, a voz poética sugere que gostar de poesia é gostar do imponderável e daquilo que não se ajusta a definições.

Trazendo a questão para âmbito do ensino, o fato de que poucos alunos gostam de poesia tem lá seus fundamentos. Em parte, o contato do aluno com o gênero se dá de modo muito rarefeito em seu percurso escolar, na exata medida em que a prosa atende com maior presteza às solicitações gramaticais e aos estudos linguísticos do texto literário, consideradas as práticas de maior rendimento nos Ensinos Fundamental e Médio. No âmbito do Ensino Superior, a questão primeiramente diz respeito à estruturação das disciplinas que separam a prosa da poesia, como se tal limite existisse de fato. Ao que parece, a linha divisória entre uma e outra se assenta em uma visão clássica de gêneros literários, um vetor desde há muito tempo inaceitável por conta dos desmontes das fôrmas literárias e do desvanecimento das fronteiras entre formas procedimentos já legitimados no âmbito da criação poética, das perquirições teóricas e do exercício da crítica. Entretanto, as demarcações de fronteiras, além do caráter isolante (isso é isso; aquilo é aquilo), encerram uma grande 
contradição entre o que se prega e o que se realiza, uma vez que as orientações curriculares recomendam o ensino através de gêneros.

$\mathrm{Na}$ há meio termo. A prosa sobressai, como bem demonstra a sua marcante presença em congressos, seminários, linhas de pesquisa, chamadas para publicação; enfim, a prosa desponta com notoriedade em diferentes práticas acadêmicas. Por isso, é natural que o aluno, estando mais habituado a saborear um cardápio dominado pela prosa, estranhe o paladar da poesia, quando não se dá a devida atenção ao trânsito existente entre prosa e poesia: a prosa poética, o poema em prosa. Mas estranhar não significa rejeição total, pois o exercício da docência demonstra que alunos, antes refratários a ela, podem mudar de ponto de vista.

$\mathrm{Na}$ verdade, o gosto é uma construção que requer tempo, convívio, protocolos de leitura. Neste sentido, a pesquisa de Christina Bielinski Ramalho, realizada na Universidade Federal de Sergipe - Campus Itabaiana, oferece resultados bem significativos sobre o gosto pela poesia. Os dados apresentados pela pesquisadora no artigo intitulado "A poesia é o mundo sendo: o poema na sala de aula", revelam que :

Do grupo identificado como do sexo feminino, a resposta "de vez em quando" à questão "Você gosta de ler poemas?" representa $53,2 \%$ do total, alcançando, pois, a maioria. O percentual das que declararam "não gostar de ler poemas" é bastante baixo (1,2\%). Do grupo identificado como "sexo masculino", os percentuais que representam o "gosto de ler" e o "de vez em quando" quase se igualaram (46,1\% e 46,4\%). Em termos gerais, o "gosto de ler poemas" alcançou margem de $39 \%$, enquanto o "gosto de ler de vez em quando" representou $52,4 \%$, o que indica um registro positivo da relação entre os discentes do curso de Letras e a leitura de poemas.

Quanto ao hábito de leitura, comparando os percentuais médios dos três grupos (sexo feminino, sexo masculino, e não identificado), destacou-se o percentual do sexo feminino que se definiu como "leitora assídua" $(28,9 \%)$, embora, também em termos gerais, seja o grupo "leitor ocasional" o mais representativo dos três grupos (64,5\%, 63,5\% e 69\%).

De outro lado, se no quadro anterior o percentual médio de estudantes que não gostam de ler poemas foi de $6 \%$, os $13,6 \%$ de "não leitores" deste quadro podem indicar que metade desse percentual envolve estudantes que afirmaram gostar de ler poemas (sempre ou de vez em quando), mas, no entanto, não o fazem.

O baixo percentual de leitores assíduos do sexo masculino, matriculados no $1^{\circ}$ período, pareceu ratificar a ideia geral de que adolescentes e jovens do sexo masculino não costumam ser apreciadores de poesia. Os percentuais dos períodos seguintes já devem ser 
considerados a partir do fato de os estudantes estarem em contato direto com o gênero lírico na universidade.

Apesar de o percentual total de estudantes do curso que gostam de ler poemas ser de $39 \%$, apenas $12,8 \%$ dos estudantes indicaram terem lido poemas sempre (antes do curso), o que parece indicar simpatia recente pelo gênero. $O$ baixo índice do hábito de leitura de poemas antes do curso de Letras também pode ser indicativo de uma realidade escolar: a maior ênfase no gênero narrativo e na leitura "obrigatória" de romances. Esse dado se confirma pelo baixo percentual de entrevistados que atribuiu à escola a função mediadora para a leitura de poemas (7\%). (BIELINSKI, 2014, p.350)

Segundo se observa, os números contabilizados pela pesquisadora reforçam o acentuado ou discreto afastamento do aluno em relação ao gênero. Ademais, os resultados da pesquisa clareiam o peso das questões de gênero na formação dos leitores de poesia e que Marcelino Freire captou tão bem no conto intitulado "Amigo do rei". Nele, através da encenação dos esforços do pai para impedir que o filho seja poeta, aflora um imaginário sociocultural que, sem dúvida, põe travas no desenvolvimento natural da formação do leitor de poesia, como bem demonstra o fragmento a seguir:

Todo menino gosta de bola. Ele nem sequer olha. Não dá mínima bola, entende? Oh! O que vai ser dele quando crescer? Resolveu perguntar. Hein? O menino sorriu. Vou ser poeta.

Agora mais essa. A mãe falou. Pelé não é compositor? Hã? E o Garrincha? O que que tem o Garrincha? Era casado com a Elza Soares, não era? O que tem a ver? Sei lá. Mundo artístico é tudo igual. Mundo artístico? O pai ficou matutando, matutando.

Bicha. É isso. Meu Deus! Gritou ele.

Meu filho vai ser bicha. Credo! (FREIRE, 2008, p.93-4)

Indo além da comicidade que aflora do comportamento caricatural da figura paterna, o conto de Marcelino Freire encena literariamente a força das construções culturais e como ela invade o espaço escolar para, se não bem administrada pelos professores, minar o gosto pela leitura, gerando conflitos internos e externos que, a princípio, não estariam relacionados à leitura em si. Portanto, quando se discute o gosto pela poesia, ou por qualquer outro gênero, as questões sociais, culturais e econômicas não podem ser descartadas, pois elas vão interferir ou mesmo respingar na formação de leitores.

Após uma longa digressão, retoma-se o poema de Wislawa Szymborska, intitulado "Alguns gostam de poesia", a fim de destacar que o não saber, quando 
assumido de forma absoluta -_ "Por mim não sei e insisto que não sei" --, tornase um ponto de apoio que impede o sujeito lírico de sofrer uma queda fatal: "e esta insistência é corrimão que me salva". Insistir em não saber o que é poesia oferece gamas de possibilidades que as respostas sempre completas e/ou satisfatórias tentam calar. Está aí um ponto relevante, porque não se resguardar em certezas vãs oferece uma perspectiva bem mais ampla sobre a poesia que extrapola a conhecida tríade: versos, sons e ritmo.

A teimosa insistência em não saber evita a queda promovida por estéreis definições teóricas que, em lugar de problematizar, buscam apagar contradições e desossar as dificuldades acarretadas por tudo aquilo que não se permite sistematizar. Ao mesmo tempo, possibilita manter o vigor do "isso" em sua plural abertura semântica, em suas infinitas possibilidades de preenchimento, porque, uma vez nomeada como "isso", a poesia se mostra esquiva a qualquer tipo de enquadramento. Portanto, sua captação não pode ser submetida à natureza do ensino, já que "Não pode nenhum poeta — nem ninguém - ter a pretensão de estabelecer rumos e regras para a poesia" (GULLAR, 2006, p.157). A indefinição acerca do que vem a ser poesia é também uma questão para os poetas, como se pode observar no poema de Wislawa Szymborska e nas palavras de Ferreira Gullar. Apenas para efeito de ênfase, vale conferir .a declaração de Guiseppe Ungaretti (1888-1970), em Razões de uma poesia e outros ensaios (1994), no capítulo intitulado "Indefinível aspiração":

Não sei se a poesia possa ser definida. Creio e professo que seja indefinível, e que se manifeste nos momentos da nossa expressão, quando o que nos é mais caro, que mais nos inquietou e atormentou em nossos pensamentos, que mais profundamente pertence à própria razão da nossa vida, nos aparece em sua verdade mais humana; mas numa vibração que parece superar a força do homem e que não pode jamais ser conquistada nem pela tradição nem pelo estudo, embora seja substancialmente solicitada a se alimentar de uma como de outro. (UNGARETTI, 1994, p. 187-188)

Embora as palavras do poeta italiano reiterem a impossibilidade de encontrar uma definição para poesia, ela pode ser sentida como um movimento de forte agitação e cuja presença se faz notar através de uma fonte de potência sobre-humana. Ressalta Ungaretti que não há como se ter a posse da poesia, 
ainda que ela busque nutrientes na "tradição" e no "estudo". Para ele, a poesia decorre de uma "experiência estritamente pessoal" (p.188), porque contém traços da subjetividade de quem a vocaliza; mas também deve comportar as marcas de "anonímia" (p.188), orquestrando, assim, uma espécie de canto coral. Este pensamento, guardadas as diferentes concepções poéticas, pode harmonizar-se com o de Ferreira Gullar, para quem "o poeta fala dos outros homens e pelos outros homens, mas só na medida em que se confunde com os demais" (GULLAR, 2006, p.158).

Cumpre destacar que os poetas aqui citados, embora de diferentes nacionalidades, pensam de modo semelhante sobre o que vem a ser poesia. As diferentes vozes, sem dúvida, mesmo que desprovidas de uma intenção didática, franqueiam a abertura de algumas portas para as salas de aula no sentido de otimizar as reflexão sobre o ensino de poesia (se isto for possível!), como por exemplo: a recepção do referido gênero, a noção de voz poética, a importância da leitura em voz alta, a habilidade da escuta atenta, o encontro de subjetividades, os olhares da crítica, a falibilidade das definições absolutas e as experiências pessoais intransferíveis, entre tantos outros pontos tão importantes quanto estes.

Uma vez mais, chama-se à cena o verso de Transtömer: "o que será para uma borboleta rebocar um batelão!" (p. 97), a fim de reforçar densidades e medições de forças presentes à formação de leitores de poesia. O sentido do verso pode bem ilustrar o que vem ocorrendo nas aulas de leitura, quando se transformam poemas canônicos em meros objetos veiculadores de informação conservados em arquivos universitários; apenas justificáveis pelas notas de rodapé e pelos glossários que, despindo a poesia de imediatez, de visão total, "de categorias e de tom", de "familiaridade" e de subjetividades (STEINER, 1991), colocam-na "fora de proporção na página real".

\section{3 - Hoje: poesia, ciência, tecnologia}

Poesia hoje, um risco a correr! Afinal, vive-se numa época em que a certeza do que venha a ser literatura já está fora de cogitação. As fronteiras da arte foram expandidas e esbatidas de tal forma que a pergunta "o que é literatura?" parece ter perdido todo o sentido. O melhor, talvez, seria perguntar o que pode ser considerado literatura nesta primeira década do século $X X I$, já que o momento 
cultural reforça postulados teóricos que enfatizam mobilidade e porosidade do texto literário.

Até aqui, foram colocados em destaque alguns pontos nevrálgicos que costumam orquestrar o coro dos que se propõem a levantar diariamente um "batelão": ensinar poesia. Leitura, leitor, conceito de poesia, gosto e voz poética são pontos que, de fato, não podem ser excluídos de uma proposta didática voltada para o ensino do gênero já mencionado. $O$ estabelecimento do cânone também não pode ficar de fora do rol dos pontos nevrálgicos já referidos, à medida que os processos de legitimação e consagração de obras foram sendo interrogados, acarretando a abertura do cânone ou mesmo o seu estilhaçamento. Mas, aos que temem o desaparecimento das vozes legitimadas, não há com que se preocupar, pois, sem que se espere, autores canônicos reaparecerem em outros suportes que não o livro e ultrapassam os limites dos espaços acadêmicos. Um significativo exemplo, hoje, encontra-se no documentário intitulado (o vento lá fora). Além de inserir no circuito fílmico uma criteriosa seleção de poemas de Fernando Pessoa, conta com as leituras magistrais de Cleonice Berardinelli e Maria Bethânia. O encontro entre a professora especialista em Fernando Pessoa e a diseuse promove não só a audição das diferentes vozes que habitam a obra do poeta português, mas também vale por uma aula sobre como se deve ler poemas. Os espectadores mais atentos irão ouvi-los como uma espécie de música nas vozes das leitoras, tendo ainda a oportunidade de comprovar que a leitura de poemas exige estudo dos textos, observação de claves, tons, compassos, tempo, ritmo, prosódia, projeção e expansão de voz, etc...

Sobre a constatação de todos os tempos de que leitores de poesia são escassos, a coleção "Leve um livro", organizada por Bruno Brum e Ana Elisa Ribeiro, sob a chancela da lei de incentivo à cultura de Belo Horizonte, quer reverter este quadro, pois tem por meta distribuir gratuitamente 2.500 exemplares de cada título publicado "em 20 pontos da capital mineira - bares, cinemas, Mercado Central, rodoviária —-", sendo que "os PDFs ficam disponíveis para baixar, também de graça, no site "leveumlivro.com.br", de acordo com a reportagem de Alice Sant'Anna. Até o momento, foram publicados É proibido pisar na grama, de Chacal, e Arquitetura de interiores, de Ana Martins Marques. 
Os exemplos acima ilustram muito bem que as teses alarmistas sobre a situação da poesia parecem estimular saídas para impedir que elas se instalem confortavelmente. Há sempre confronto e movimentos de reversão contextual. Não se pode negar que foi a própria crise da leitura que desencadeou políticas públicas mais inclusivas e que incentivou parcerias entre artistas, bibliotecários, contadores de histórias, estudantes, médicos, pedagogos, professores, voluntários, com o propósito de desenvolver projetos leitura de cunho educacional, social e terapêutico. A esta mesma crise se deve ainda a ampliação dos espaços de leitura. Bares, centros culturais, hospitais, igrejas, instituições asilares, teatros, entre outros, exigiram novas configurações e novos formatos para que a leitura se realizasse em suas respectivas dependências.

Outro ponto que a princípio é visto com reserva diz respeito à relação entre poesia e tecnologia. Homens e mulheres, hoje, vivem assistidos por máquinas. Computadores, celulares, televisores, vídeo-reprodutores, tablets, i-pads. iphones regulam, monitoram, otimizam, entre outras possibilidades, as vidas de muitos habitantes da Terra. Por isso, com toda razão, a acesso ao espaço digital veio a se constituir em um importante item no IDH (Índice do desenvolvimento humano).

Face à visível relação entre vida humana e tecnologia, já era esperado que as convergências entre literatura e tecnologia também viessem a vingar, promovendo um forte abalo nas definições canônicas de texto, livro, autor e leitor, bem como reivindicando novas configurações para a criação poética. Nesta perspectiva, a passagem do táctil para o digital irá desmontar a conhecida definição de texto como "corpo discursivo estruturado segundo certas leis concretas de composição" (SIMONE, 1998, p. 243), pois o texto vai adquirir uma estrutura aberta enquanto reescritura intertextual conectada a redes, nexos e percursos que rompem com o modelo de pensamento linear e promovem diferentes formas de interação, como destaca George P. Landow (1995, p. 15). A hipertextualidade, além de introduzir uma nova concepção de texto, repropõe para os clássicos conceitos de autor e livro reconfigurações, já que as "funções do escritor e do leitor se entrelaçam de forma mais estreita que em qualquer outro momento" (LANDOW, 1995, p. 95), porque a desestruturação e a descontinuidade ferem o conceito de centro legitimado pela forma do livro, enquanto objeto acabado. Sublinha-se ainda que a concepção de autoria, antes resguardada de 
qualquer suspeição pelas normas de impressão e pelos mecanismos legais e jurídicos, perde a soberania e submete-se às manifestações da subjetividade do leitor.

Destaca-se que as concepções de leitor e leitura passam também por reconfigurações. O leitor mais ativo é também um escritor que vai interagir com 0 texto alheio, o que, da óptica hipertextual, interfere diretamente na composição das obras que lê ou apenas visita, pois escolhe fragmentos, realiza montagens ou lê sem a preocupação de seguir protocolos de leitura estabelecidos para o texto impresso, ou seja, "o leitor pode escolher seu próprio centro de investigação e experiência" (LANDOW, 1995, p. 25). Em resumo, o leitor não se enclausura em nenhuma forma de organização e tampouco se submete à rigidez dos padrões hierárquicos. Ao decidir buscar um determinado poeta ou poema, ao leitor lhe são dispostas infinitas redes que vão desde trabalhos acadêmicos, compras dos livros de autores até "leituras" não-canônicas de obras realizadas pelos bloggers, pelos usuários do $S K O O B$ e pelas comunidades do extinto Orkut.

Isto posto, redirecionando as observações para o tema central deste artigo, vale observar a estreita convergência entre poesia e tecnologia. Aqui, talvez, aborda-se um ponto delicado, porque a poesia sempre encontrou abrigo nas redomas que a defendem, por assim dizer, de se inter-relacionar com áreas de conhecimento aparentemente sem chances de diálogo. Entretanto, a pesquisa sobre poema e tecnologia, neste sentido, reserva surpresas, pois vários experimentos resultam em promissoras parcerias, como o que foi realizado em 1992, no laboratório de Sistemas Integráveis (Escola Politécnica da USP), denominado de "Vídeo Poesia - Poesia Visual". Este projeto dedicou-se a transpor poemas para a tridimensionalidade, investindo na dimensão sonora e no movimento colorizado. O projeto visava promover o diálogo entre poesia, computação gráfica e teoria da Poesia Concreta, configurando-se, pois como um trabalho de feição interdisciplinar, porque agregava poetas e pesquisadores das áreas de Engenharia Eletrônica e de Arquitetura. Os poemas selecionados para esta experiência, de acordo com Ricardo Araújo (1999) foram: "Bomba" e "SOS", de Augusto de Campos; "Femme", de Décio Pignatari; "Parafísica", de Haroldo de Campos; "Dentro" de Arnaldo Antunes; "O arco-íris no arco curvo", de Júlio Plaza.

Se o projeto mostra que as possibilidades oferecidas pela tecnologia favorecem uma realização mais materializada da proposta verbivocovisual, ele 
também expõe a distinção entre engenheiros que podem fazer programas para criar poemas conforme esquemas tradicionais (SPASMO - programa de computer poetry; POETEACH - software de criação de haicais) e os poetas que têm, por outro lado, uma obra e que se utilizam do computador para realizá-la. Por este motivo, é igualmente importante destacar que se os poetas desejam aliar perfeição técnica à estética, o profissional de engenharia traça objetivos mais pragmáticos, o que pode gerar, durante o processo, intervenções e divergências, como esta relatada por Ricardo Araújo:

No processo de animação das imagens é que se evidencia a diferença de concepções entre poeta e técnicos. É nessa fase que se concretizam alguns choques que já estavam previstos no roteiro. [...] No primeiro caso, aos técnicos não agradava um vermelho puro (magenta) como cor dominante no poema. Alegavam, com toda a razão, que para o vídeo, o vermelho (magenta) acarretaria uma série de problemas (ocasiona manchas, provoca distorções) e comprometeria a nitidez dos significantes "Poema/Bomba". Augusto de Campos, por questões estéticas, insistiu no vermelho: para espanto dos engenheiros, as manchas e as distorções comprometeram minimamente a nitidez. (ARAÚJO, 1999, p.24)

Através da reconstituição de um episódio entre Augusto de Campos e os técnicos, fica muito claro como se desenvolvem as relações entre poetas e engenheiros e como as divergências podem ser ultrapassadas quando está em jogo o estético. Entretanto, o diálogo entre poesia e tecnologia não se realiza apenas através de projetos que necessitam ser assistidos por técnicos especializados. O diálogo pode realizar-se de outros modos.

Entre os poetas contemporâneos, por exemplo, Ramon Mello (1984), em Vinis Mofados (2009), promove o diálogo com a tecnologia pelo acionamento de um léxico tipicamente digital, como se consta nos poemas "Internerd" e "Poema digital". Já em Poemas tirados de notícias de jornal (2012), utiliza o sampler como procedimento estético e de criação poética, tão bem explicitado no "Poema atravessado pelo manifesto sampler"; ou no "Poema tirado de um jornal virtual", dando uma clara amostra da voz de Manuel Bandeira em versão tecnológica. Angélica Freitas (1973) também, em seu último livro, Um útero é do tamanho de um punho (2012), reafirma o diálogo que vem encetando de diferentes modos com a tecnologia. Na série "3 poemas com o auxílio do Google" pratica a 
googlagem — um modo de compor já bem difundido por Flarf poetry, embora este movimento não esteja exclusivamente relacionado ao Google.

Insistindo na relação entre poesia e tecnologia, não se pode omitir, hoje, o nome de Eduardo Kac (1962), que ficou conhecido nos anos 80 ao trabalhar com holografia digital. De acordo com as palavras do artista, "Vídeo, holografia, programação, dispositivos portáteis e Internet têm expandido as possibilidades e o alcance da nova poesia" (KAC, 2008, p. 327). Se o poeta pensa assim, o ensino de poesia parece não dar a devida atenção à poesia que se realiza em diálogo com a tecnologia e com as ciências. Como muito bem diz o poeta, "Agora, diante de um mundo de clones, quimeras e seres transgênicos" assume ele que há que se buscar novos caminhos "para a poesia in vivo", através da utilização da "biotecnologia e de organismos vivos como um novo campo para a criação verbal." (Idem).

Sem dúvida, são muito inquietantes e provocadores os experimentos apresentados por Eduardo Kac, se relacionados ao ensino de poesia. Como seria, talvez, a reação de alunos, acostumados às concepções canônicas sobre o texto literário e sobre a literatura, ao se depararem com as seguintes propostas ${ }^{1}$ de Eduardo Kac:

3) Interação dialógica com mamíferos marinhos: componha um texto sonoro manipulando parâmetros gravados de tom e frequência da comunicação de golfinhos, para uma audiência de golfinhos. Observe como uma audiência de baleias responde e vice-versa.

4) Poesia transgênica: sintetize $A D N$ de acordo com códigos inventados para escrever palavras e frases usando combinações de nucleotídeos. Incorpore essas palavras e frases de ADN no genoma de organismos vivos, os quais, então, serão passados aos seus descendentes, combinando com as palavras de outros organismos. Por meio da mutação, perda natural e do intercâmbio de ADN, novas palavras e sentenças surgirão. Leio o transpoema novamente como sequenciamento do ADN mutante. (KAC, 2008, p.328)

Não se pode negar que tais propostas criam uma área de desconforto por que ferem consideravelmente certos diálogos tidos como aceitáveis no âmbito da

\footnotetext{
${ }^{1}$ Estas propostas se relacionam à Biopoesia (Biopoetry). Cf. "Poesia que é criada para ser realizada in vivo." (KAC, 2013, p.322). Trata-se de uma proposta que utiliza a biotecnologia e organismos vivos "como um novo campo para a criação verbal." (KAC, 2008, p.327)
} 
poesia. Ainda há muita reação quando se topa com esta expansão de limites da arte de maneira geral. Se o projeto de Silvio Romero em aproximar a poesia da ciência no século XIX gerou reações muito afetadas, o que dizer quando a poesia dialoga com campos do saber como a biologia, a robótica e a computação, de modo mais radical possível. Muita perplexidade, dirão. Contudo, se o ensino de poesia assumir um perfil mais ousado, alunos e professores poderão trilhar por esses caminhos ainda não bem demarcados (por isso plenos de insegurança!) no âmbito dos planos, das ementas, das linhas de pesquisa e dos planejamentos, buscando abrir mais uma porta - sem desconsiderar as já existentes - que possa franquear o desenvolvimento de "novos modelos filosóficos e políticos" (bem como educacionais; interferência do autor do artigo) e "influenciar novos tipos de sinergias que vão surgindo na fronteira em que o orgânico e o digital se encontram (KAC, 2013, p. 246).

Então, para o encerramento desse artigo, o verso do poeta sueco Tomas Tranströmer torna a esvoaçar sobre essas notas acerca do ensino de poesia hoje: "o que será para uma borboleta rebocar um batelão!". Agora, no melhor dos exercícios propostos pela perversidade contemporânea, desconstrói-se o sentido que a ele se deu inicialmente, pois o ensino de poesia, inspirado pela "Poesia espacial"2, poderá libertar-se do peso, das densidades, das forças, ao se aventurar por "uma nova linguagem poética que participa da criação de uma nova cultura espacial através da exploração das potencialidades criativas da hipogravidade e da ausência de peso." (KAC, 2008, p.336)

\section{Referências bibliográficas}

ARAÚJO, Ricardo. Poesia Visual-Vídeo Poesia. São Paulo: Perspectiva, 1999. Coleção Debates; n. 275

BARROS, Manuel. Retrato do artista quando jovem. Desenhos de Millôr Fernandes. Rio de Janeiro: Record, 1998.

\footnotetext{
${ }^{2}$ Cf. "Poesia espacial é a poesia concebida, feita para e vivida em um contexto de microgravidade ou de gravidade nula. Em outras palavras, a poesia espacial é aquela que exige e explora a ausência de peso como meio de escrita." (KAC, 2008, p. 336)

"A poesia espacial é baseada no tempo, no sentido de que cada poema contém sua própria lógica temporal. Ela é performativa, pois o corpo do leitor é sem peso e está, portanto, engajado em uma experiência de leitura de uma sinestesia particular. Os poemas espaciais estão naturalmente ligados às artes visuais e a outras disciplinas porque eles não podem existir em um livro, e sim na ausência de gravidade." (Idem)
} 
BELIENSKI, Cristina Ramalho. Revista da Anpoll, no 36, p. 330-370, Florianópolis, Jan./Jun. 2014.

BORGES, Jorge Luis. Esse ofício do verso. Organização de Calin-Andrei Mihailescu. São Paulo: Companhia das Letras, 2000.

DOMENECK, Ricardo. Bruit Pur Pour Les Brutes - Dos sentidos do som. In: Sons: Arranjos: Garganta. São Paulo: Cosac Naify: Rio de Janeiro: Viveiros de Castro Editora, 2009. (Coleção Ás de colete; v. 22)

DUFRENNE, Mikel. O poético.Tradução de Luiz Arthur Numes e Reasylvia Kroeff de Souza. Supervisão e apresentação de Angelo Ricci. Porto Alegre: Globo, 1969.

FREIRE, Marcelino. O amigo do rei. In: Gravuras de Manu Maltez. Rio de Janeiro, Record, 2008.

Rasif: mar que arrebenta.

FREITAS, Angélica. 3 Poemas com auxílio do Google.In: Um útero é do tamanho de um punho. São Paulo: Cosac Naify, 2012.

GULLAR, Ferreira. Poesia e realidade. In: (uma luz do chão). Rio de Janeiro: José Olympio, 2006.

Sobre a arte Sobre poesia:

LANDOW, George P. Hipertexto: la convergência de la teoria crítica contemporânea y la tecnologia. Barcelona: Paidós, 1992. Hipermedia; n. 2 KAC, Eduardo. Biopoesia; Poesia Espacial. In: Alea: Estudos neolatinos, Rio de Janeiro, v.10, n.2, p.327-336, jul./dez., 2008.

Telepresença e Bioarte: humanos, coelhos \& robôs em rede. Tradução de Antonio de Pádua Danesi. São Paulo: Editora da Universidade de São Paulo, 2013.

MELLO, Ramon. Poema atravessado pelo manifesto sampler; Poema tirado de um jornal virtual. In: Janeiro: Móbile, 2012. Poemas tirados de notícias de jornal. Rio de . Vinis mofados. Rio de Janeiro: Língua Geral, 2009. (Coleção Língua real)

PAZ, Octavio. A outra voz. Tradução de Wladir Dupont. São Paulo: Siciliano, 1993.

SANT'ANNA, Alice. A poesia vai aonde o povo está: nas ruas de BH. In: O Globo, Rio de Janeiro, 12 dez. 2014. Segundo Caderno, p. 4.

SIMONE, Raffaele. El cuerpo del texto. In: NUNBERG, George (comp.). El futuro del libro. Barcelona: Paidós, 1998. Multimedia; n. 8

STEINER, George. Linguística e poética. In: Extraterritorial. Tradução de Júlio Castañon Guimarães. São Paulo: Companhia das Letras, 1990. 
SZYMBORSKA, Wislawa. Alguns gostam de poesia. In: Paisagem com grão de areia. Tradução de Júlio Sousa Gomes. Lisboa: Relógio d’Água, 1998.

TRANSTRÖMER, Tomas. Furacão islandês. In: 50 poemas. Tradução do sueco e nota introdutória de Alexandre Pastor. Lisboa: Relógio d’Água, 2012.

UNGARETTI, Guiseppe. Razões de uma poesia e outros ensaios. Organização de Lúcia Wataghin, tradução de Liliana Laganá, Lucia Wataghin, Maria Betânia Amoroso. São Paulo: Editora da Universidade de São Paulo: Imaginário,1994. 
Artigo recebido em: 16 de dezembro de 2014

Artigo aprovado em: 25 de março de 2015

Sobre o autor:

Armando Gens Filho é professor associado da Universidade do Estado do Rio de Janeiro e professor do Curso de Especialização em Estudos Literários da Faculdade de Formação de Professores da Universidade do Estado do Rio de Janeiro. 